\title{
Long-acting morphine following hip or knee replacement: A randomized, double-blind, placebo-controlled trial
}

\author{
Shirley L Musclow MN RN (EC) ${ }^{1}$, Tabatha Bowers MN RN (EC) ${ }^{2}$ \\ Hanna Vo BScPh ${ }^{3}$, Mark Glube MD FRCPC ${ }^{4}$, Thong Nguyen BScPT ${ }^{5}$
}

\begin{abstract}
SL Musclow, T Bowers, H Vo, M Glube, T Nguyen. Long-acting morphine following hip or knee replacement: A randomized, double-blind, placebo-controlled trial. Pain Res Manage 2012;17(2):83-88.
\end{abstract}

BACKGROUND: Patients undergoing total hip or knee replacement surgery experience unmanaged pain during postoperative physiotherapy sessions. It was theorized that a baseline opioid would improve pain management.

OBJECTIVES: To examine the effectiveness of adding long-acting oral morphine to a routine postoperative regimen for total hip or knee replacement surgery.

METHODS: The present study was a double-blind, randomized, placebocontrolled trial for patients undergoing total hip or knee replacement surgery. All patients received routine postoperative analgesia; in addition, the treatment group received long-acting oral morphine $30 \mathrm{mg}$ orally twice daily for three days, while the control group received placebo capsules. The primary end point was a decrease in pain scores by two points on a 0 - to 10 -point pain rating scale. Secondary end points included adverse effects, acute confusion, pain-related interferences in function and sleep, length of stay and patient satisfaction.

RESULTS: Two hundred patients were enrolled in the present study (March 2004 to March 2006). Although the groups were large enough to yield statistical significance, most pain scores did not reach the predetermined improvement for clinical significance. Additionally, there was an increase in opioid usage $(\mathrm{P}<0.0001)$, vomiting $(\mathrm{P}=0.0148)$ and oversedation $(\mathrm{P}=0.08)$. There were no statistically significant changes in function or sleep. Improved satisfaction with pain management was minimal $(\mathrm{P}=0.052)$.

DISCUSSION: The present study was undertaken to determine the value of adding a long-acting opioid (morphine) to the usual care of patients undergoing total hip or total knee replacement surgery. The results yielded minimally improved pain scores and additional adverse effects (vomiting and oversedation). Published research in which long-acting opioids (oxycodone) were used for similar postoperative procedures did not robustly report improved pain scores. In addition, patients using a long-acting opioid (oxycodone) during the postoperative period reported somnolence, dizziness and confusion. Statistically, the patients in the present study showed higher confusion scores and no improvement for pain-related interferences with activity or walking. The treatment group did report increased satisfaction; however, the significance was weak.

CONCLUSIONS: Thirty milligrams twice per day of long-acting morphine from days 1 to 3 following total hip and total knee replacement surgery provided minimal improvements in pain scores, and more adverse effects in the treatment group. The overall strength of evidence for improved outcomes is minimal and thus not supported.

Key Words: Acute pain; Long-acting morphine; Opioids; Postoperative pain; Total hip replacement; Total knee replacement

$\mathrm{T}$ he management of postoperative pain has improved over the past decade due to more informed clinicians, enhanced pain management modalities (epidural, intrathecal and patient-controlled analgesia [PCA]), as well as the use of a multimodal approach (nonsteroidal anti-inflammatory drugs [NSAIDs], acetaminophen,

\section{La morphine à action prolongée après une arthroplastie totale de la hanche ou du genou : un essai à double insu aléatoire et contrôlé contre placebo}

HISTORIQUE : Les patients qui subissent une arthroplastie totale de la hanche ou du genou ressentent des douleurs non soulagées pendant les séances de physiothérapie postopératoires. Il est postulé qu'un opioïde de fond améliorerait la prise en charge de la douleur.

OBJECTIFS : Examiner l'efficacité d'ajouter de la morphine à action prolongée par voie orale à la posologie postopératoire systématique d'une arthroplastie totale de la hanche ou du genou.

MÉTHODOLOGIE : La présente étude était un essai à double insu aléatoire et contrôlé contre placebo auprès de patients ayant subi une arthroplastie totale de la hanche ou du genou. Ils ont tous reçu systématiquement des analgésiques après l'opération. De plus, le groupe traité prenait $30 \mathrm{mg}$ de morphine à action prolongée par voie orale deux fois par jour pendant trois jours, tandis que le groupe témoin prenait des capsules de placebo. Le paramètre ultime primaire était une diminution de deux points des indices de douleur sur une échelle de zéro à dix. Les paramètres ultimes secondaires incluaient les effets indésirables, une confusion aiguë, des interférences de la fonction et du sommeil liées à la douleur, la durée d'hospitalisation et la satisfaction du patient. RÉSULTATS : Deux cents patients ont participé à la présente étude (de mars 2004 à mars 2006). Même si les groupes étaient assez importants pour avoir une signification statistique, la plupart des indices de douleur n'atteignaient pas le taux d'amélioration prédéterminé pour avoir une signification clinique. De plus, on constatait une augmentation de l'utilisation d'opioïdes $(\mathrm{P}<0,0001)$, des vomissements $(\mathrm{P}=0,0148)$ et une sursédation $(\mathrm{P}=0,08)$. Il n'y avait pas de changements significatifs de la fonction ou du sommeil. Lamélioration de la satisfaction à l'égard de la prise en charge de la douleur était minime ( $\mathrm{P}=0,052)$.

EXPOSÉ : Les auteurs ont entrepris la présente étude pour déterminer la valeur d'ajouter un opioïde à action prolongée (morphine) aux soins habituels des patients subissant une arthroplastie totale de la hanche ou du genou. Les résultats ont suscité une amélioration minimale des indices de douleur et des effets indésirables supplémentaires (vomissements et sursédation). Les recherches publiées dans lesquelles on avait utilisé des opioïdes à action prolongée (oxycodone) dans le cadre d'interventions postopératoires similaires ne faisaient pas état d'améliorations robustes des indices de douleur. De plus, les patients qui utilisaient un opioïde à action prolongée (oxycodone) pendant la période postopératoire déclaraient de la somnolence, des étourdissements et de la confusion. Sur le plan statistique, les patients qui ont participé à la présente étude affichaient des indices de confusion plus élevés et aucune amélioration des interférences liées à la douleur en cas d'activité ou de marche. Le groupe traité se disait plus satisfait, mais la signification des résultats était faible. CONCLUSIONS : L'administration de $60 \mathrm{mg}$ de morphine à action prolongée par jour entre le premier et le troisième jour suivant une arthroplastie totale de la hanche ou du genou favorisait une amélioration minimale des indices de douleur et plus d'effets indésirables dans le groupe traité. La qualité globale des preuves d'amélioration des issues est minime, donc non étayée.

opioids and regional analgesia). Despite these advancements, inadequate pain control persists. In Canada, as many as $25 \%$ of surgical inpatients reported their average pain to be severe or extreme (1). VanDenKerkhof and Goldstein (2) suggest that more than 72,000 new cases of chronic postsurgical pain occurred in Canada over a

Departments of ${ }^{1}$ Nursing, Acute Pain Services; ${ }^{2}$ Nursing, Geriatrics; ${ }^{3}$ Pharmacy; ${ }^{4}$ Anesthesiology; ${ }^{5}$ Physiotherapy, The Scarborough Hospital,

Toronto, Ontario

Correspondence: Ms Shirley L Musclow, Lawrence S Bloomberg Faculty of Nursing, University of Toronto, 155 College Street, Suite 130,

Toronto, Ontario M5T 1P8. Telephone 416-978-4985, fax 416-978-8222, e-mail shirley.musclow@utoronto.ca 
one-year period after selected surgeries, including total hip replacement (THR) and total knee replacement (TKR). Clearly, additional strategies in pain management warrant exploration.

The acute pain service (APS) team, working with one of the country's largest postoperative orthopedic populations, identified gaps in pain management for patients following THR and TKR surgery. As improved organizational patient flow initiatives for this population began to take place within our organizations and across the province, the team focused on improved pain care within the immediate postoperative period. APS patients are typically provided with regional, patient-controlled and multimodal analgesia. However, a number of orthopedic patients continued to experience inadequate pain control, potentially interfering with joint rehabilitation or compromising recovery. As-needed administration of analgesia (ie, PCA) may be contributing to inadequate pain control due to individual variations among patients. Administering analgesia to maintain constant serum opioid levels may provide a baseline of analgesia, thus improving pain control for these patients. Long-acting opioids (LAO) have been primarily used to treat malignant and nonmalignant pain. Nine published studies that evaluated the use of LAO for acute pain after surgery were identified (3-11). Eight of these studies examined the use of long-acting oxycodone, and one studied long-acting morphine preoperatively (10). No double-blind, randomized, placebo-controlled studies to date have evaluated the efficacy and safety of adding a LAO to a PCA+NSAID regimen in the immediate postoperative period.

The objective of the present study was to evaluate the efficacy of adding LAO to the usual care (postoperative PCA+acetaminophen+ NSAID). Differences in pain, pain-related interferences, and adverse effects between the control (usual care) and treatment (usual care plus LAO) group were explored.

\section{METHODS}

Ethics approval was granted from The Scarborough Hospital Research Ethics Board (Toronto, Ontario). All patients scheduled for THR or TKR surgery were identified through the hospital preadmission clinic schedule. They were approached by the APS nurse practitioner (NP) or geriatric clinical nurse specialist (CNS). Exclusion criteria included the inability to swallow capsules, the inability to speak or read English, and patients with sleep apnea or true morphine and related opioid allergies. There were no age restrictions. Informed written consent was obtained. A study number was assigned to each patient on enrollment and recorded at the top of the orders for treatment document that was part of the patient chart. This form was then sent to the pharmacy department where patients were then allocated to one of two groups using a computer-generated table of random numbers. The randomization list was generated using permuted-block randomization.

Patients received the allocated group intervention from the pharmacist according to the generated list. The list was located in the hospital pharmacy department and concealment of the allocated intervention was maintained at enrollment. Study patients, nurses, physicians and all study personnel were blinded. Only the study pharmacist was unblinded, but she had no contact with study participants. Study numbers were reassigned to the next seen patient if a patient withdrew from the study before admission to hospital. If a patient withdrew from the study after treatment was initiated, that patient was still followed as intention-to-treat.

Participants were screened for cognitive function and acute confusion at enrollment using the Folstein Mini Mental Status Exam (12) and the Neecham acute confusion tool $(13,14)$. Other baseline data included pain rating at rest and with activity on the day of the preadmission visit, current history of pain longer than six months, current analgesic usage, Timed Up and Go score (TUG) (15), and self-reported sleep ratings (4-point Likert scale [poor, fair, good or very good]).

Patients received the usual care of anesthetics and analgesia during surgery, and in the immediate postoperative period (day 0) until postoperative day 1 (D1PO). Usage data relating to analgesics and medications to counteract opioid-related side effects were collected. All patients received routine postoperative analgesia (usual care) consisting of PCA (morphine [1 $\mathrm{mg}$ to $2 \mathrm{mg}$ every $5 \mathrm{~min}$ ] or in a few cases, hydromorphone [0.2 $\mathrm{mg}$ to $0.4 \mathrm{mg}$ every $5 \mathrm{~min}]$ ) as needed postsurgery until D2PO (approximately $48 \mathrm{~h}$ ); NSAID for up to D4PO (rofecoxib [unless contraindicated] $50 \mathrm{mg}$ daily starting D1PO). Rofecoxib $(n=69)$ was changed to celecoxib $200 \mathrm{mg}$ daily $(n=14)$ when it was removed from the market in October 2004. Celecoxib was then changed to ketorolac ( $10 \mathrm{mg}$ intravenously every $6 \mathrm{~h}$ for four doses, then ibuprofen $400 \mathrm{mg}$ orally three times daily) when cyclooxygenase 2 inhibitors became a concern in December $2004(n=75)$. Ibuprofen was chosen because it was the only available NSAID on the hospital formulary that was commonly used within this population. On discontinuation of PCA, patients received as-needed oxycodone $5 \mathrm{mg}$ plus acetaminophen $325 \mathrm{mg}$ one to two by mouth every $3 \mathrm{~h}$.

In addition to the usual care, patients in the treatment group received morphine sulfate ( $\mathrm{M}$-Eslon, Aventis Pharma Inc, Canada) $30 \mathrm{mg}$ by mouth every $12 \mathrm{~h}$ for six doses starting D1PO at 09:00 while the control group received placebo capsules (Wiler, Canada) at the same dosing times. The pharmacy department prepared the active study medication by transferring the contents of M-Eslon $30 \mathrm{mg}$ capsules to the same opaque blue and maroon gelatin capsules that were used as placebos. The exact identity of the study drug was verified during the dispensing process by comparing the lot number on each package against the lot number in the prepack log maintained during the manufacturing process. Although long-acting oxycodone has been used in more studies of this nature than long-acting morphine, morphine was chosen because it is the gold standard for postoperative pain control and is less expensive. A dose of $30 \mathrm{mg}$ of M-Eslon was determined, from the authors' clinical experience and the few available studies in the literature, to be a safe and effective baseline dosage. The pharmacist dispensed a three-day supply (six capsules) of placebo or M-Eslon for each patient according to the randomization schedule.

The randomization code was revealed to the investigators and attending physicians in instances where the treatment was stopped for safety concerns or serious adverse events. Patients were followed during hospitalization until discharge or up to four days. All patients were followed by the APS (anesthesiologist and NP) until PCA discontinuation. The APS NP continued to follow patients (up to four days).

Patients were instructed to complete self-report diaries while in hospital. Each patient recorded daily pain scores, adverse effects and sleep ratings until discharge (up to four days). Pain was recorded at rest and with activity (morning, afternoon and evening) on a combined Faces Pain Scale-Revised (16,17) and numerical pain rating scale. Adverse effects (nausea, vomiting, pruritus, drowsiness, dizziness, constipation, other) and sleep ratings were documented daily.

On D3PO, patients also completed the Brief Pain Inventory (BPI) for pain-related interferences $(18,19)$. Questions included pain intensity ratings and interference in function and sleep related to pain. Patients were also asked on D3PO to rate "How satisfied were you with your pain management" on an 11-point Likert scale (0 to 10 ).

Patients were assessed daily by the geriatric CNS or APS NP for acute confusion using the Neecham Confusion Scale. Pain-related interferences with activities were evaluated by the TUG and BPI tools. TUGs were completed by physiotherapists, physiotherapy assistants or advanced practice nurses (CNS, NP). Patients were instructed to stand up from a standard chair with armrests, walk $3 \mathrm{~m}$ to a marking on the floor, turn around and sit back into the chair. The time required to complete the task preoperatively and on D2PO to D4PO was recorded. The usage of analgesics and medications to counteract opioid side effects (eg, laxatives, antiemetics, antihistamines) was also recorded.

The primary end point for the study was an improvement in pain intensity scores by two points on the 11-point Likert scale (Faces Pain Scale-Revised) (20). The SD of pain intensity scores was estimated to be 5 . Secondary end points included adverse effects, confusion, pain- 
TABLE 1

Demographics and clinical characteristics of patients

\begin{tabular}{lccc}
\hline & $\begin{array}{c}\text { Usual care } \\
(\mathbf{n}=\mathbf{9 3})\end{array}$ & $\begin{array}{c}\text { Usual care + LAO } \\
(\mathbf{n}=\mathbf{9 7})\end{array}$ & $\mathbf{P}$ \\
\hline Sex & & & \\
$\quad$ Female, $\mathrm{n}$ & 54 & 49 & 0.3 \\
$\quad$ Male, $\mathrm{n}$ & 39 & 48 & \\
Age, years & $64 \pm 11.45$ & $67 \pm 3.93$ & 0.79 \\
Height, cm & $165 \pm 10.05$ & $170 \pm 9.98$ & 0.61 \\
Weight, kg & $80 \pm 20.53$ & $82 \pm 16.43$ & 0.92 \\
Surgical procedure & & & \\
$\quad$ Total hip replacement, $\mathrm{n}$ & 55 & 53 & 0.53 \\
$\quad$ Total knee replacement, $\mathrm{n}$ & 38 & 44 & \\
Baseline pain at rest & $2.9 \pm 1.8$ & $2.4 \pm 2.0$ & 0.08 \\
Baseline pain with activity & $5.1 \pm 1.9$ & $4.5 \pm 2.3$ & 0.055 \\
Neecham & $29.9 \pm 0.2$ & $29.9 \pm 0.3$ & 0.8143 \\
MMSE & $27.9 \pm 2.4$ & $27.5 \pm 2.8$ & 0.5061 \\
\hline
\end{tabular}

Data presented as mean \pm SD unless otherwise specified. LAO Long-acting opioid; MMSE Mini Mental Status Exam; Neecham Neecham confusion scale

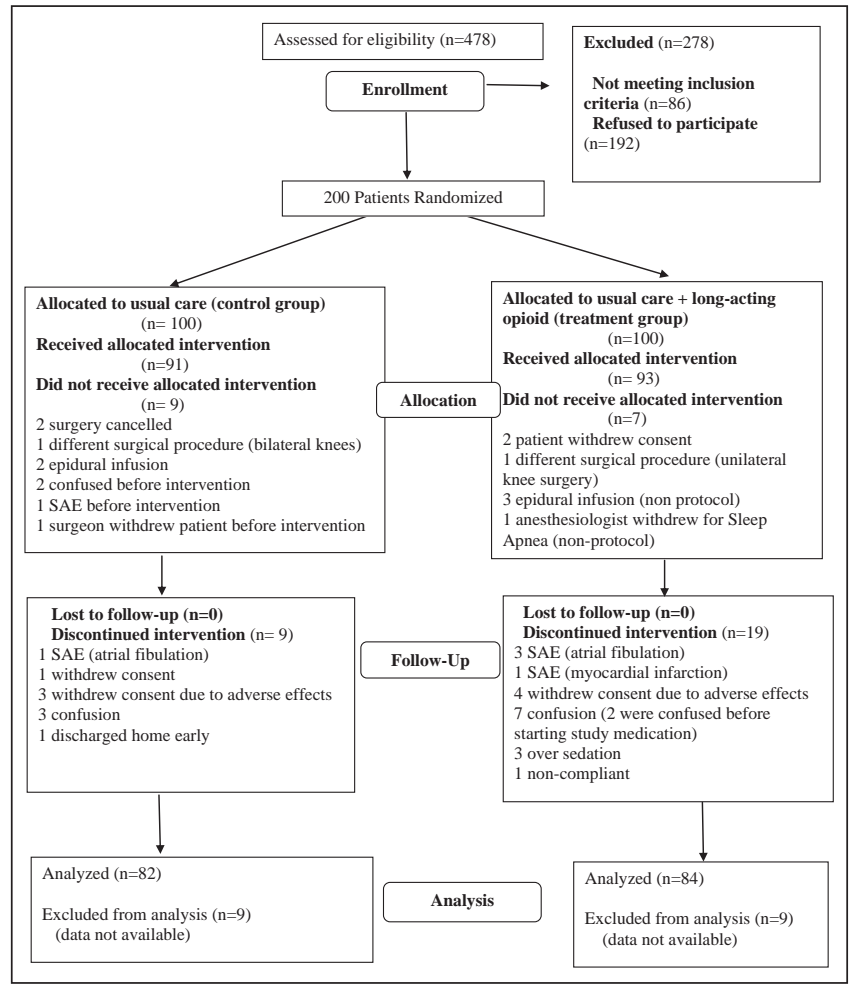

Figure 1) Flow diagram of study. SAE Serious adverse event

related interferences in function, sleep, length of stay and satisfaction with pain management. The required sample size for detecting at least a two-point change in scores at 5\% type I error (two-sided) and $80 \%$ power was calculated to be 100 patients in each group, allowing for attrition. Adverse events (respiratory depression, oversedation, atrial fibrillation, myocardial infarction and acute confusion) were reported to the research ethics board.

Two independent sample $t$ tests or Wilcoxon tests were used for comparing the means of continuous variables, while the $\chi^{2}$ test was used for comparing categorical variables. A repeated measures ANOVA was used for comparing intensity scores over time between the two groups.
TABLE 2

Primary end point: Pain intensity*

\begin{tabular}{ccccc}
\hline & Usual care & Usual care + LAO & Difference $(95 \% \mathrm{Cl})$ & $\mathbf{P}$ \\
\hline Morning & & & & \\
$\quad$ Rest & $3.13 \pm 1.97$ & $2.53 \pm 1.96$ & $-0.60(-1.19$ to -0.01$)$ & 0.046 \\
Activity & $5.51 \pm 1.92$ & $4.74 \pm 2.24$ & $-0.77(-1.40$ to -0.14$)$ & 0.017 \\
Afternoon & & & & \\
$\quad$ Rest & $2.69 \pm 1.97$ & $2.39 \pm 2.15$ & $-0.30(-0.92$ to 0.322$)$ & 0.343 \\
Activity & $5.00 \pm 2.01$ & $4.44 \pm 2.48$ & $-0.56(-1.24$ to 0.126$)$ & 0.109 \\
Evening & & & & \\
Rest & $2.82 \pm 2.05$ & $2.19 \pm 2.10$ & $-0.64(-1.27$ to -0.00$)$ & 0.049 \\
Activity & $4.82 \pm 2.10$ & $4.30 \pm 2.48$ & $-0.52(-1.22$ to 0.18$)$ & 0.147 \\
\hline
\end{tabular}

Data presented as mean $\pm S D$ unless otherwise specified. *Self-reported patient diary postoperative day 1 to postoperative day 4. LAO Long-acting opioid

TABLE 3

Brief Pain Inventory scores on postoperative day 3

\begin{tabular}{lcccc}
\hline & Usual care & $\begin{array}{c}\text { Usual care } \\
+ \text { LAO }\end{array}$ & $\begin{array}{c}\text { Difference } \\
(95 \% \mathrm{Cl})\end{array}$ & $\mathbf{P}^{*}$ \\
\hline Worst pain in past 24 $\mathrm{h}$ & $\begin{array}{c}6.47 \pm 2.72 \\
(\mathrm{n}=83)\end{array}$ & $\begin{array}{c}5.56 \pm 3.06 \\
(\mathrm{n}=82)\end{array}$ & $\begin{array}{c}0.91 \\
(0.026 \text { to 1.79) }\end{array}$ & 0.0456 \\
Least pain in past 24 $\mathrm{h}$ & $2.02 \pm 2.23$ & $1.63 \pm 2.04$ & 0.39 & 0.2393 \\
& $(\mathrm{n}=83)$ & $(\mathrm{n}=81)$ & $(-0.26$ to 1.04$)$ & \\
Average pain in past 24 h & $3.93 \pm 2.12$ & $3.34 \pm 2.36$ & 0.59 & 0.0984 \\
& $(\mathrm{n}=81)$ & $(\mathrm{n}=81)$ & $(-0.10$ to 1.28$)$ & \\
Pain right now & $2.66 \pm 2.52$ & $2.44 \pm 2.57$ & 0.22 & 0.5868 \\
& $(\mathrm{n}=80)$ & $(\mathrm{n}=79)$ & $(-0.57$ to 0.59) & \\
\hline
\end{tabular}

Data presented as mean $\pm S D$ unless otherwise specified. *For a difference of 2 . LAO Long-acting opioid

\section{RESULTS}

Baseline data

Both groups were similar in age, sex, surgical procedure (only total joint replacements and not unilateral or bilateral knee replacement), history of hip- or knee-related pain lasting longer than six months, previous opioid and NSAID usage $(\mathrm{P}=0.39)$, and history of other chronic pain (Table 1). At enrollment (clinic visit), patients were similar for baseline pain (rest and activity), acute confusion (Neecham, Folstein Mini Mental Status Exam) and function (TUG). The treatment group reported better sleep ratings at enrollment. There were no statistical differences for sedating or opioid medications between the groups on the day of surgery (including the operating room).

\section{Number of participants}

Two hundred subjects were recruited to participate from March 2004 to March 2006. Data from the present study (subjects who met the inclusion and exclusion criteria) were analyzed with intention-to-treat and included all allocated patients (Figure 1). Eighteen of 184 patients were lost to follow-up. Therefore, 166 patients were available for intention-to-treat analysis. Seven patients violated protocol, which left 159 patients for per-protocol analysis (Figure 1).

Primary outcome: Pain intensity

Although statistically significant, the treatment group failed to demonstrate evidence of clinically significant improvements in pain scores of at least two points on a 0 to 10 numerical rating scale in the morning (both at rest by $0.60[\mathrm{P}=0.046]$ and with activity by $0.77[\mathrm{P}=0.017])$ and in the evening at rest by $0.64(\mathrm{P}=0.049)$. There were no differences for the afternoon ratings or pain with movement in the evening (Table 2). Pain score reductions of one to two points are accepted to be clinically important (20). Additional questions related to pain were asked using the BPI tool on D3PO. There was no statistical significance between groups for the BPI questions about pain experienced during the previous $24 \mathrm{~h}$ with the exception of a weak significant finding for 
TABLE 4

Secondary end points: Adverse effects

\begin{tabular}{|c|c|c|c|c|c|c|c|c|c|c|c|c|c|c|c|c|}
\hline \multirow[b]{2}{*}{ Group } & \multicolumn{4}{|c|}{ D1PO } & \multicolumn{4}{|c|}{ D2PO } & \multicolumn{4}{|c|}{ D3PO } & \multicolumn{4}{|c|}{ D4PO } \\
\hline & $\mathbf{n}$ & $\mathbf{N}$ & $\%$ & $\mathbf{P}$ & $\mathbf{n}$ & $\mathbf{N}$ & $\%$ & $\mathbf{P}$ & $\mathbf{n}$ & $\mathbf{N}$ & $\%$ & $\mathbf{P}$ & $\mathbf{n}$ & $\mathbf{N}$ & $\%$ & $\mathbf{P}$ \\
\hline \multicolumn{17}{|l|}{ Nausea } \\
\hline Usual care + LAO & 40 & 86 & 46.5 & 0.6474 & 32 & 80 & 40.0 & 0.2548 & 27 & 79 & 34.2 & 0.0769 & 21 & 69 & 30.4 & 0.5679 \\
\hline Usual care & 43 & 85 & 50.6 & & 26 & 84 & 31.0 & & 17 & 81 & 21.0 & & 17 & 69 & 24.6 & \\
\hline \multicolumn{17}{|l|}{ Drowsy } \\
\hline Usual care + LAO & 56 & 86 & 65.1 & 0.3218 & 41 & 79 & 51.9 & 0.5323 & 25 & 78 & 32.1 & 1.0000 & 22 & 69 & 31.9 & 0.5738 \\
\hline Usual care & 62 & 85 & 72.9 & & 39 & 84 & 46.4 & & 26 & 80 & 32.5 & & 18 & 68 & 26.5 & \\
\hline \multicolumn{17}{|l|}{ Vomiting } \\
\hline Usual care + LAO & 17 & 86 & 19.8 & 1.0000 & 6 & 80 & 7.5 & 0.7820 & 12 & 79 & 15.2 & 0.0148 & 11 & 69 & 15.9 & 0.1825 \\
\hline Usual care & 16 & 85 & 18.8 & & 8 & 84 & 9.5 & & 3 & 81 & 3.7 & & 5 & 69 & 7.2 & \\
\hline \multicolumn{17}{|l|}{ Puritis } \\
\hline Usual care + LAO & 28 & 86 & 32.6 & 0.2694 & 23 & 80 & 28.8 & 0.6133 & 27 & 79 & 34.2 & 0.1140 & 15 & 69 & 21.7 & 0.5143 \\
\hline Usual care & 35 & 85 & 41.2 & & 28 & 84 & 33.3 & & 18 & 81 & 22.2 & & 11 & 69 & 15.9 & \\
\hline \multicolumn{17}{|l|}{ Dizziness } \\
\hline Usual care + LAO & 29 & 86 & 33.7 & 0.8708 & 16 & 80 & 20.0 & 0.1518 & 13 & 79 & 16.5 & 1.0000 & 12 & 69 & 17.4 & 1.0000 \\
\hline Usual care & 27 & 86 & 31.4 & & 26 & 84 & 31.0 & & 14 & 81 & 17.3 & & 11 & 69 & 15.9 & \\
\hline \multicolumn{17}{|l|}{ Other } \\
\hline \multicolumn{17}{|l|}{ Usual care + LAO } \\
\hline Usual care & & & & & & & & & 1 & 64 & 1.6 & & & & & \\
\hline
\end{tabular}

D1PO, D2PO, D3PO, D4PO Postoperative days 1, 2, 3, 4; LAO Long-acting opioid

TABLE 5

Secondary end point: Confusion

\begin{tabular}{lccc}
\hline & $\begin{array}{c}\text { Usual } \\
\text { care }\end{array}$ & $\begin{array}{c}\text { Usual care }+ \\
\text { LAO }\end{array}$ & $\mathbf{P}$ \\
\hline $\begin{array}{c}\text { Study drug stopped for confusion } \\
\text { and/or oversedation, } \mathrm{n}(\%)\end{array}$ & $3(3.3)$ & $10(11)$ & 0.08 \\
$\begin{array}{l}\text { Neecham score*, mean } \pm \text { SD } \\
\text { Neect }\end{array}$ & $29.14 \pm 0.61$ & $28.70 \pm 1.82$ & 0.02 \\
\hline
\end{tabular}

*Neecham scores of 0 to $19=$ moderate to severe acute confusion; 20 to $24=$ mild or early development of acute confusion; >24 = no confusion. LAO Longacting opioid

\section{TABLE 6}

Secondary end point: Function*

\begin{tabular}{lccc}
\hline & $\begin{array}{c}\text { Usual care, } \\
\mathbf{n = 8 2}\end{array}$ & $\begin{array}{c}\text { Usual care }+ \text { LAO, } \\
\mathbf{n = 8 4}\end{array}$ & $\mathbf{P}$ \\
\hline $\begin{array}{c}\text { Pain related interference } \\
\text { with general activity }\end{array}$ & $4.42 \pm 2.98$ & $3.95 \pm 2.98$ & 0.3275 \\
$\begin{array}{l}\text { Pain related interference } \\
\text { with walking ability }\end{array}$ & $4.54 \pm 3.04$ & $4.73 \pm 3.28$ & 0.7063 \\
\hline
\end{tabular}

Data presented as mean $\pm S D$ unless otherwise specified. *Brief Pain Inventory scores on postoperative day 3. LAO Long-acting opioid

the worst pain over the past $24 \mathrm{~h}$, which was less for the treatment group $(\mathrm{P}=0.0456)$ (Table 3$)$.

Adverse effects

Data analysis revealed directional trends toward more adverse effects (nausea, vomiting, pruritus, dizziness) for the treatment group, with vomiting on $\mathrm{D} 3 \mathrm{PO}$ achieving statistical significance $(\mathrm{P}=0.0148)$ (Table 4). Medications used to treat adverse effects (diphenhydramine, dimenhydrinate, ondansetron, metoclopramide, lactulose, magnesium hydroxide, glycerin suppository, sodium phosphate, naloxone) were also tracked. There was no statistical significance between groups for use of these medications.

A statistical significance was found for acute confusion scores for the treatment group $(28.70 \pm 1.82$ versus $29.14 \pm 0.61 ; \mathrm{P}=0.02)$, which was not clinically significant. Study medication was stopped for more patients in the treatment group $(n=10 ; 11 \%)$ due to confusion and oversedation than the control group $(\mathrm{n}=3 ; 3.3 \%)(\mathrm{P}=0.08)$ (Table 5).
TABLE 7

Secondary end point: Sleep*

\begin{tabular}{lccc}
\hline & Usual care & Usual care + LAO & $\mathbf{P}$ \\
\hline D1PO & $0.67 \pm 0.83$ & $0.87 \pm 0.90$ & 0.1236 \\
D2PO & $0.84 \pm 0.78$ & $1.24 \pm 0.98$ & 0.0041 \\
D3PO & $1.00 \pm 0.95$ & $1.29 \pm 0.94$ & 0.0510 \\
D4PO & $1.09 \pm 0.99$ & $1.49 \pm 0.99$ & 0.0180 \\
\hline
\end{tabular}

Brief Pain Inventory scores on D3PO

\begin{tabular}{lccc}
\hline & Usual care & Usual care + LAO & $\mathbf{P}$ \\
\hline $\begin{array}{l}\text { Pain related interference } \\
\text { with sleep }\end{array}$ & $4.48 \pm 3.30$ & $2.87 \pm 2.69$ & 0.0009 \\
\hline
\end{tabular}

Data presented as mean $\pm S D$ unless otherwise specified. *Self-reported patient diary postoperative day 1 to postoperative day 4 (D1PO to D4PO). $0=$ poor; 1 = fair; 2 = good; 3 = very good. LAO Long-acting opioid

Function

There was no statistical difference between groups for pain-related interference with general activity or walking ability at $72 \mathrm{~h}$ postsurgery on the BPI. TUG function tests during the last half of the study were jeopardized by the lack of physiotherapist time to continue to participate in the study. There was an insufficient amount of data to analyze the TUG test results (Table 6).

\section{Sleep}

The treatment group reported a significant decrease in pain-related interference with sleep (BPI) at $72 \mathrm{~h}$ postsurgery $(\mathrm{P}=0.0009)$. However, the daily diary entries for sleep, once adjusted for differences at baseline, showed no overall differences between the groups during a four-day period using analysis of covariance with repeated measurements (Table 7).

Satisfaction with pain management

The treatment group reported higher satisfaction scores (8.01) on a scale of 0 to 10 versus the control group (7.22). However, the statistical significance was weak $(\mathrm{P}=0.0526)$. 


\section{Length of stay}

During the first half of the study $(n=101)$, a decrease of 1.4 days length of stay for the treatment group was found. Unfortunately for the present study, the hospital changed the discharge criteria for total joint replacement surgery at the midpoint of the study $(n=101)$. Surgeons discharged patients according to one of two options for length of stay. This program resulted in a substantial reduction in length of stay for these patients and, therefore, negated generalizable conclusions overall.

\section{Medication usage}

There was no difference between groups for NSAID type and usage. Opioid usage was calculated over a three-day period (D0PO to D2PO). The total intravenous morphine-equivalent (Appendix 1) usage over a three-day period was statistically greater for the treatment group (125 mg versus $88 \mathrm{mg} ; \mathrm{P}<0.0001$ ).

The treatment group used fewer oxycodone + acetaminophen tablets (5.23) compared with the control group (6.94). However, although this was statistically significant $(\mathrm{P}=0.0194)$, fewer than two tablets overall was not considered to be clinically significant.

\section{DISCUSSION}

The present study explored an additional option for managing pain after TKR and THR surgery.

The results of the present study found limited benefits of adding a LAO (morphine) for acute pain management after TKR and THR surgery. Patients receiving LAO in addition to usual care reported minimally improved pain scores. This is similar to results of previous studies: Kerpsack and Fankhauser (5) found no difference when patients used LAO (oxycodone) after total joint arthroplasty, and deBeer et al (3) reported a decrease in pain only at discharge (5.5 days length of stay) for patients using LAO (oxycodone) after knee or hip replacement. Illgen et al (11) found no difference in pain scores when oxycodone was compared with intravenous PCA. The initial study using LAO (oxycodone) for acute pain reported significantly improved pain scores; however, the sample size was small (9). Todd et al (20) caution that a large body of literature has been published without addressing the question of clinical significance for pain scores. They suggest that at minimum, changes in acute pain scores $<1.3$ ( $13 \mathrm{~mm}$ on a $100 \mathrm{~mm}$ visual analogue scale) have no clinical importance, and that a 1.6-point decrease is most likely a more appropriate minimum value.

Additional opioids can contribute to additional adverse effects. Patients receiving LAO in the present study did use more opioids overall, and consequently reported increased vomiting and experienced increased oversedation. Other authors have reported additional adverse effects such as somnolence, dizziness and confusion in patients receiving LAO (oxycodone) during the postoperative period $(3,4,10)$. Cheville et al (9) did not report adverse effect data. However, this was during the postoperative rehabilitation period rather than the immediate postoperative period.

A large number of patients undergoing THR or TKR surgery are elderly and, as such, are at risk for acute confusion. Given that $20 \%$ to $60 \%$ of patients in this demographic experience acute confusion, it is also associated with increased morbidity and mortality and nursing home placement. Thus, this was a concern when adding a background opioid to the postoperative regimen $(21-24)$. Acute confusion scores overall were within normal limits for both groups in the present study. However, statistically, the treatment group had higher acute confusion scores $(\mathrm{P}=0.02)$.

We found a significant improvement for pain-related interference with sleep (D3PO) for patients receiving LAO. However, this finding was not supported by the overall daily diary sleep ratings which, once adjusted for baseline, showed no statistical significance. There was also a weak statistical significance for improved satisfaction with patients receiving $\mathrm{LAO}(\mathrm{P}=0.0526)$. No other studies were found to report on sleep or patient satisfaction evaluations while using LAO during the immediate postoperative period. Cheville et al (9) reported improved function for rehabilitation patients following unilateral knee replacement surgery, after using LAO (oxycodone) (9). We found no differences in pain-related interferences for activity or walking on D3PO in our patient population.

To our knowledge, the present report is the first published randomized, placebo-controlled, double-blind study using LAO (morphine or oxycodone) in the acute immediate postoperative population. There are several limitations to the present study. The investigators enrolled the patients themselves, thus introducing possible selection bias. The assignment of anesthesiologists and surgeons for the surgical procedure could not be controlled. The study protocol for specific NSAIDs changed according to Health Canada safety concerns. Due to hospital formulary restrictions, the present study used long-acting morphine and not oxycodone - the drug reported in most publications. An additional limitation was the possibility that drug loss occurred during pharmacy preparation of study capsules (ie, transfer of M-Eslon capsules to study capsules). The study drug dosage was kept constant, and was not adjusted for age and weight; however, subjects were randomized and groups were large.

There are no tested, valid, reliable tools for postoperative sedation and, therefore, we did not operationalize the term oversedation. Oversedation in the present study was often a surgeon's decision; however, it was agreed by the investigators in each case that there was a safety concern and thus a serious adverse event. Although the NP provided most follow-up visits after discontinuation of PCA, the geriatric CNS conducted several of these visits during the study, introducing possible inter-rater reliability limitations.

The results of the present study do not support our original proposal to add LAO to usual care of managing pain after THR or TKR surgery. Although there were some improvements in pain, they were not strong indicators of success, and were offset by the significant increase in vomiting and oversedation. From a safety perspective, the addition of LAO necessitates more indepth daily assessments of the postoperative patient on an ongoing basis to determine the individual need and appropriateness of its use. Further research, and possibly alternative LAOs or other drug combinations, are needed before generally integrating LAO into usual care for postoperative pain management.

APPENDIX 1: Opioids were converted to intravenous morphine equivalent as follows: $10 \mathrm{mg}$ intravenous morphine $=30 \mathrm{mg}$ M-Eslon by mouth $=$ oxycodone $20 \mathrm{mg}=75 \mathrm{mg}$ meperidine intramuscular injection $=2 \mathrm{mg}$ hydromorphone intravenously $=200 \mathrm{mg}$ codeine by mouth .

ACKNOWLEDGEMENTS: The authors thank the Scarborough Hospital for supporting this research. Specific thanks go to the Scarborough Hospital orthopedic nurses (including PACU and surgical units), Pharmacy, Anesthesia, Orthopedic surgeons, and of course, our patients. Thank you to Dr Deanna Telner for her assistance in editing the manuscript.

DISCLOSURES: The authors have no financial disclosures or conflicts of interest to declare.

\section{REFERENCES}

1. Rocchi A, Chung F, Forte L. Canadian survey of postsurgical pain and pain medication experiences. Can J Anaesth 2002;49:1053-6.

2. VanDenKerkhof EG, Goldstein DH. The prevalence of chronic post surgical pain in Canada. Can J Anaesth 2004;51:A20.

3. deBeer J, Winemaker M, Donnelly G, et al. Efficacy and safety of controlled-release oxycodone and standard therapies for postoperative pain after knee or hip replacement. Can J Surg 2005;48;277-83.

4. Sunshine A, Olson N, Colon A, et al. Analgesic efficacy of controlled-release OxyCodone in postoperative pain.

J Clin Pharmacol 1996;36:595-603.

5. Kerpsack J, Fankhauser R. The use of controlled-release versus scheduled oxycodone in the immediate postoperative period following total joint arthroplasty. Orthopedics 2005;28:491-4. 
6. Czarnecki M, Jandrisevits M, Theiler S, Martz M, Weisman J. Controlled-release oxycodone for the management of pediatric postoperative pain. J Pain Symptom Manage 2004;27:379-86.

7. Gammaitoni A, Galer B, Bulloch S, et al. Randomized, doubleblind, placebo-controlled comparison of the analgesic efficacy of oxycodone $10 \mathrm{mg} /$ acetaminophen $325 \mathrm{mg}$ versus controlled-release oxycodone $20 \mathrm{mg}$ in postsurgical pain. J Clin Pharmacol 2003;43:296-304

8. Kampe S, Warm M, Kaufmann J, Hundegger S, Mellinghoff $\mathrm{H}$, Kiencke P. Clinical efficacy of controlled-release oxycodone $20 \mathrm{mg}$ administered on a 12-h dosing schedule on the management of postoperative pain after breast surgery for cancer.

Curr Med Res Opin 2004;20:199-202.

9. Cheville A, Chen A, Oster G, McGarry L, Narcessian E. A randomized trial of controlled-release oxycodone during inpatient rehabilitation following unilateral total knee arthroplasty. J Bone Joint Surg Am 2001;83:572-6.

10. Bellissant E, Estèbe, JP, Sébille V, Ecoffey C. Effect of preoperative oral sustained-release morphine sulfate on postoperative morphine requirements in elective spine surgery. Fundam Clin Pharmacol 2004; 18:709-14

11. Illgen R, Pellino T, Gordon D, Butts S, Heiner J. Prospective analysis of a novel long-acting oral opioid analgesic regimen for pain control after total hip and knee arthroplasty. J Arthroplasty 2006;21:814-20.

12. Folstein MF, Folstein SE, McHugh PR. Mini-Mental State. A practical method for grading the cognitive state of patients for clinicians. J Psychiatr Res 1975;12:189-98.

13. Champagne MT, Neelon VJ, McConnel ES, Funk S. The Neecham confusion scale: Assessing acute confusion in the hospitalized and nursing home elderly. Gerontologist 1987;27:4A
14. Matsushita T, Matsushima E, Maruyama M. Early detection of postoperative delirium and confusion in a surgical ward using the Neecham confusion scale. Gen Hosp Psychiatry 2004;26:158-63.

15. Podsiadlo D, Richardson S. The timed "up and go": A test of basic functional mobility for frail elderly persons. J Am Geriatr Soc 1991;39:142-8.

16. Hicks CL, von Baeyer CL, Spafford P, van Korlaar I, Goodenough B. The Faces Pain Scale-Revised: Toward a common metric in pediatric pain measurement. Pain 2001;93:173-83.

17. Herr KA, Mobily PR, Kohout FJ, Wagenaar D. Evaluation of the Faces Pain Scale for use with the elderly. Clin J Pain 1998;14:29-38.

18. Cleeland CS, Ryan KM. Pain assessment: Global use of the brief pain inventory. Ann Acad Med 1994:23:129.

19. Mendoza R, Chen C, Brugger A, et al. The utility and validity of the modified brief pain inventory in a multiple-dose postoperative analgesic trial. Clin J Pain 2004;20:357-62.

20. Todd KH, Funk KG, Funk JP, Bonacci R. Clinical significance of reported changes in pain severity. Ann Emerg Med 1996;27:485-9.

21. Segatore M, Adams D. Managing delirium and agitation in elderly hospitalized orthopaedic patients: Part 1 - theoretical aspects. Orthop Nurs 2001;20:31-43.

22. Schuurmans D, Duursma S, Shortridge-Baggett L. Early recognition of delirium: A descriptive review. J Clin Nurs 2001;6:721-9.

23. Wakefield B. Risk for acute confusion on hospital admission. Clin Nurs Res 2002;11:153-72.

24. Hart B, Birkas J, Lachmann M, Saunders L. Promoting positive outcomes for elderly persons in the hospital: Prevention and risk factor modification. AACN Clin Issues 2002;13:22-33. 


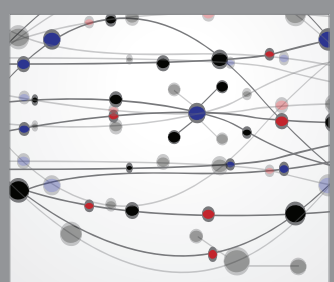

The Scientific World Journal
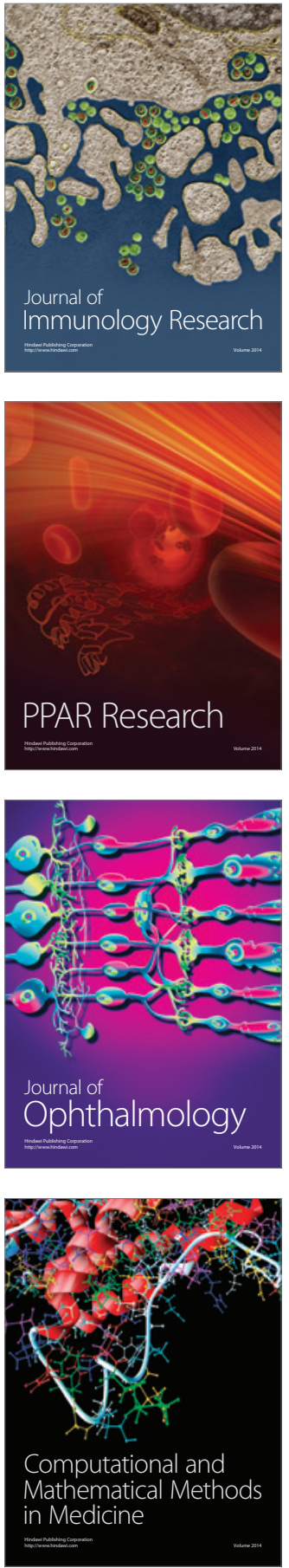

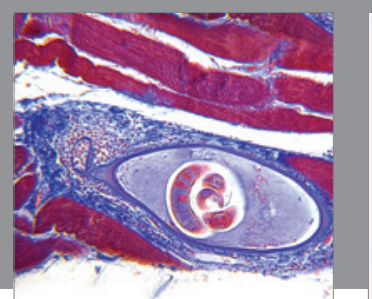

Gastroenterology Research and Practice

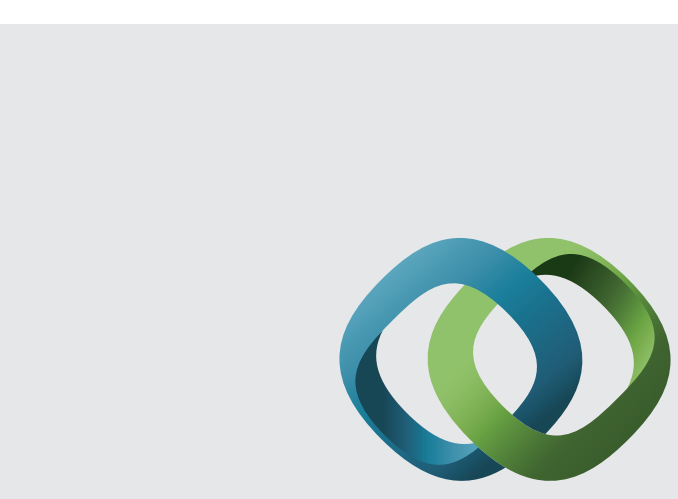

\section{Hindawi}

Submit your manuscripts at

http://www.hindawi.com
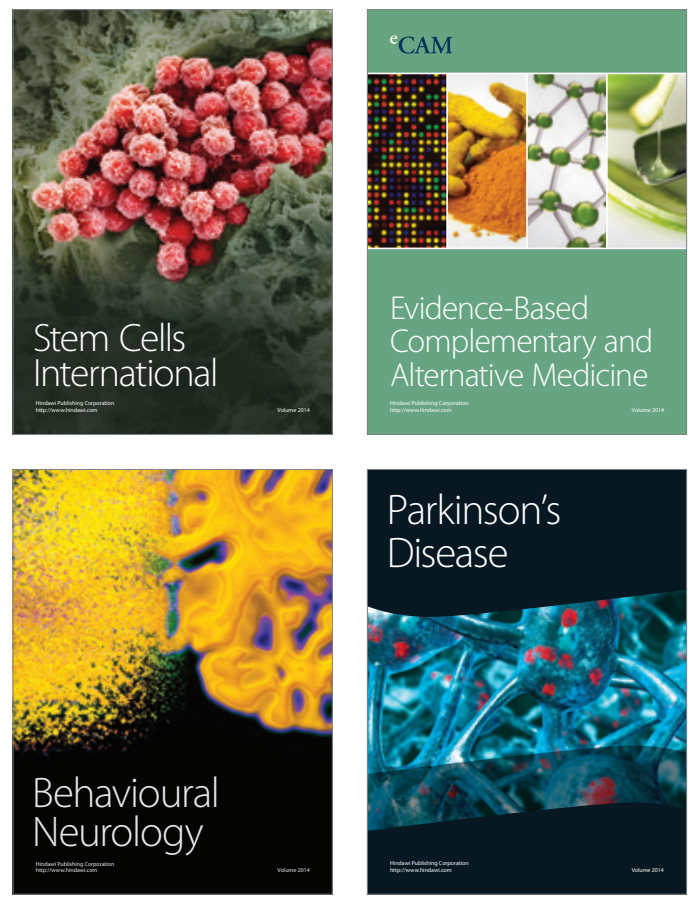
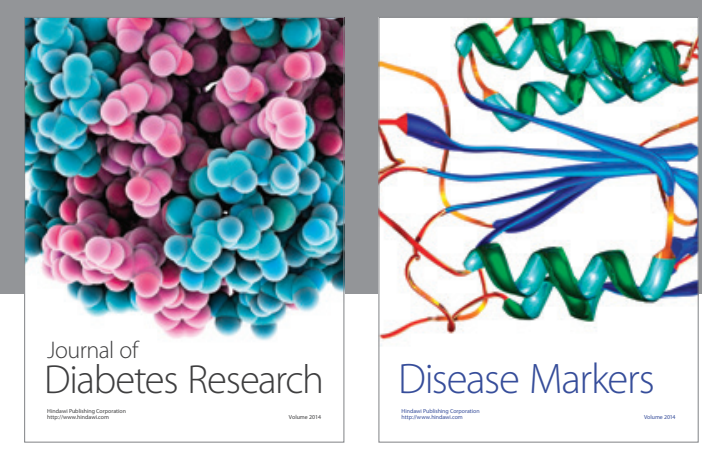

Disease Markers
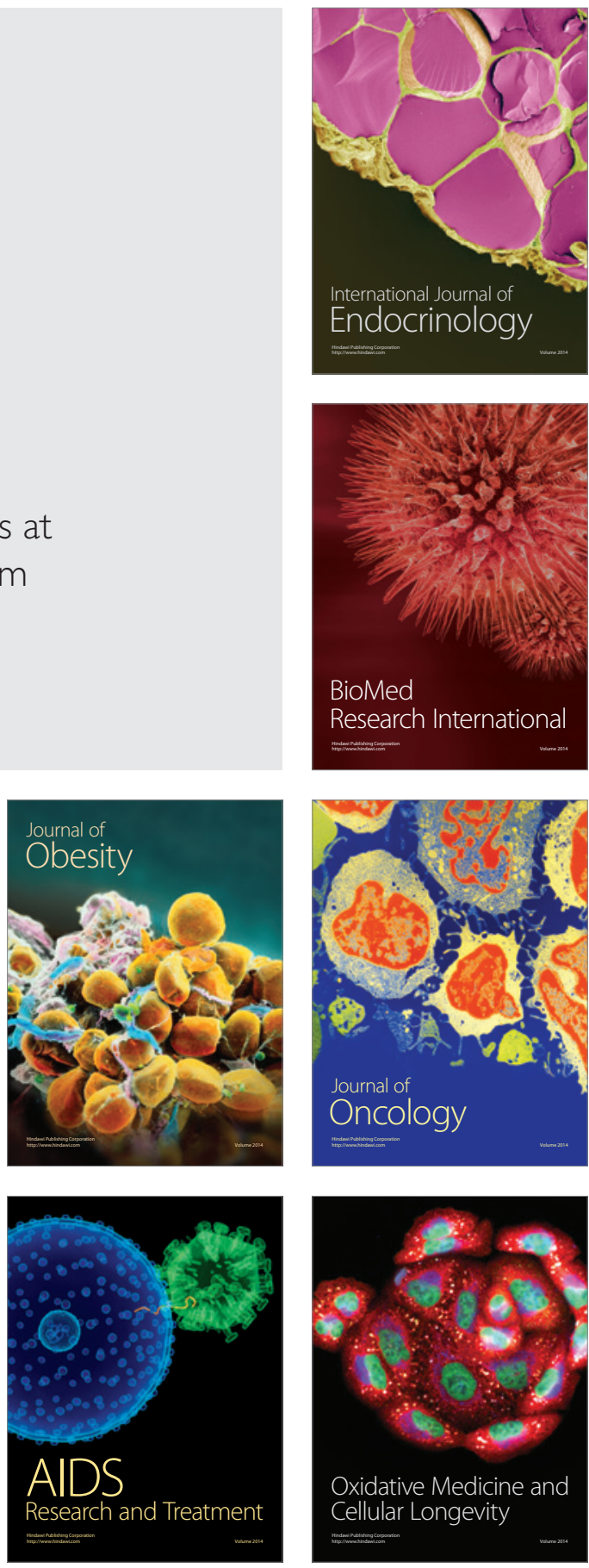